\title{
Why aren't more doctors talking about climate change?
}

\author{
n Cite as: CMAJ 2019 April 1;191:E375-6. doi: 10.1503/cmaj.109-5731
}

Posted on cmajnews.com on Mar. 12, 2019.

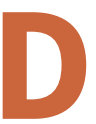
octors have a history of driving change to combat health threats. But despite warnings that climate change poses a major threat to human health, many doctors lack awareness and confidence that they can make a difference.

The world has 12 years to limit global warming to 1.5 degrees Celsius above preindustrial levels. Beyond that point, even a half-a-degree increase will threaten the stability of food and water supplies, housing and health systems worldwide, according to the United Nation's Intergovernmental Panel on Climate Change. Canadian doctors are already seeing an increase in harms related to environmental changes; many of their patients were affected by wildfires, air pollution, floods, storms and heat waves last year.

"That's at one degree of warming," says Dr. Courtney Howard, president of the Canadian Association of Physicians for the Environment. "We think we can survive two degrees. We're on track for four to five degrees within the lifetime of children currently alive."

Despite the urgency of the situation, climate change is only now beginning to appear on medical conference agendas. Few physicians address planetary health in their practices. Health systems remain major polluters. And environmental advocacy is still a niche interest outside the mainstream of medicine.

"Formal medical structures have been slow to respond," says Howard. Often physicians are simply unaware of the threat, she says. "In many cases, people are unwittingly getting misinformation because they're learning about it sideways through the media."

As of 2015, no medical school in Canada had training on climate change. The
Canadian Federation of Medical Students is drafting curricular competencies they hope to see implemented by 2020. "Traditionally, we're taught to treat the patient in front of you, treat the disease, and we don't have a lot of emphasis on the upstream social or ecological determinants of health," says Finola Hackett, chair of the group's Health and Environment Adaptive Response Task Force.

Even when physicians recognize the health threats posed by climate change, "they don't necessarily see that they can do anything about it," she says.

The scale of the challenge posed by climate change can be daunting for doctors already grappling with increasing time pressures and burnout. Howard says she suffered dysthymia for months after the world's climate "diagnosis" landed with her. Other doctors have told her they experienced similar feelings of hopelessness and low mood related to climate change.

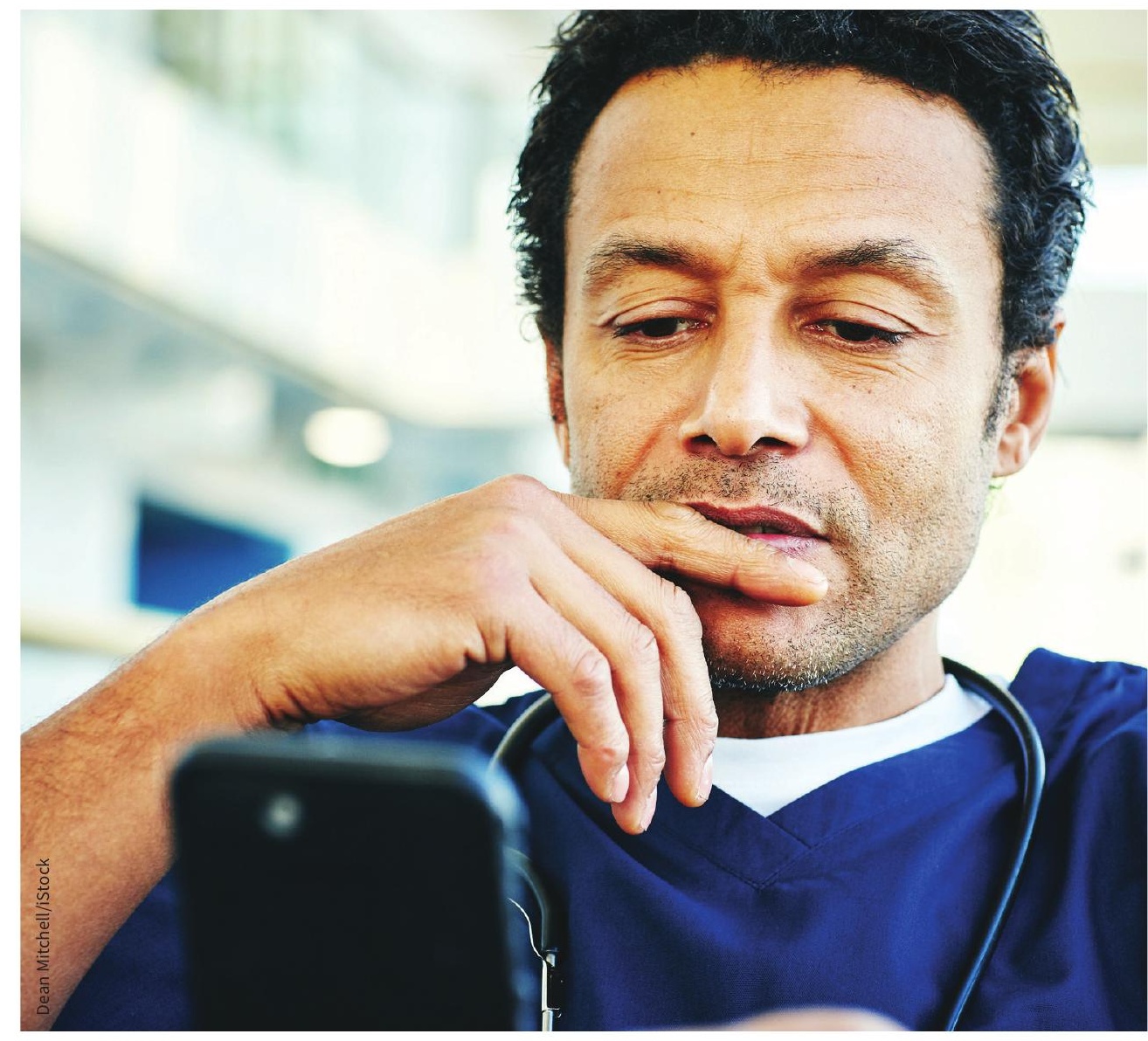

Doctors may feel helpless about climate change but shouldn't underestimate their collective influence, advocates say. 
It's an understandable reaction given that the problem can't be solved by small, individual actions, says Dr. Mary-Wynne Ashford, past copresident of the International Physicians for the Prevention of Nuclear War. About a hundred corporations account for most of the emissions contributing to global warming, and the environmental footprints of militaries aren't even counted.

However, physicians shouldn't underestimate their collective power to influ- ence governments to intervene, Ashford says. Their advocacy about the health consequences of nuclear warfare turned the tide of public opinion, leading to a deescalation of tensions during the Cold War. Mikhail Gorbachev, the former leader of the Soviet Union, said two things changed his thinking about nuclear weapons, according to Ashford. "One was his meetings with doctors, and the other was the hundreds, thousands, of letters he got from little children."
Physicians rank among Canadians' most trusted messengers, Howard says. In Canada, doctors have won commitments to a coal phase-out and influenced development of a food guide that supports planetary health. Tackling climate change as a health problem motivates action, she adds. "If we frame this like we framed tobacco, it just becomes something we solve together."

Lauren Vogel, CMAJ 